\title{
HIV Pre-exposure Prophylaxis Use and Persistence among Black Ciswomen: "Women Need to Protect Themselves, Period"
}

\author{
Maria Pyra $^{1,2}$ (D) Amy K. Johnson ${ }^{3,4} \cdot$ Samantha Devlin $^{2} \cdot$ A. Ziggy Uvin ${ }^{2} \cdot$ Shemeka Irby $^{5} \cdot$ Eric Stewart ${ }^{1} \cdot$ Cori Blum $^{1}$. \\ Maya Green ${ }^{1} \cdot$ Sadia Haider $^{6} \cdot$ Lisa R. Hirschhorn $^{4}$ • Jessica P. Ridgway ${ }^{4}$
}

Received: 14 December 2020 / Revised: 1 February 2021 / Accepted: 7 March 2021 / Published online: 17 March 2021

(C) W. Montague Cobb-NMA Health Institute 2021

\begin{abstract}
Background Disparities in HIV incidence and PrEP use among Black ciswomen remain. We examine factors associated with PrEP persistence using mixed methods.

Setting Black ciswomen in Chicago, IL, prescribed PrEP at a federally qualified health center (FQHC).

Methods We used electronic health data to determine PrEP persistence (Proportion of Days Covered $\geq 86 \%$ at 6 months) and tested demographic and clinical factors in logistic regressions. We interviewed eight Black ciswomen, purposefully selected by PrEP persistence.

Results Among 112 Black ciswomen, 18\% were persistent. In adjusted models, neighborhood, visit reason (at initiation), and initiation year were significantly associated with persistence. Qualitatively, we found little evidence of cost or adherence as barriers; participants reported low community awareness, importance of providers, and concerns around stigma, side effects, and pregnancy while using PrEP.

Conclusion While persistence among Black ciswomen was low, patients were often making decisions based on perceived HIV risk. We identified real-world barriers to address in future interventions.
\end{abstract}

Keywords HIV PrEP $\cdot$ Ciswomen $\cdot$ Black $\cdot$ Mixed methods

\section{Introduction}

HIV incidence remains relatively high among Black ciswomen in the USA; in 2018, 19\% of new HIV infections were in ciswomen, with more than half of those among Black ciswomen [1]. However, HIV pre-exposure prophylaxis (PrEP) uptake has been slow, as women are only $6 \%$ of PrEP users and the PrEP-toneed ratio was 1.6 for women compared to 5.7 for men, indicating fewer users relative to new HIV infections $[2,3]$.

Maria Pyra

mariap@howardbrown.org

Howard Brown Health, Chicago, IL, USA

2 Department of Medicine, University of Chicago, Chicago, IL, USA

3 Ann \& Robert H. Luries Children's Hospital of Chicago, Chicago, IL, USA

4 Feinberg School of Medicine, Northwestern University, Chicago, IL, USA

5 Dominican University, River Forest, IL, USA

6 Department of Obstetrics-Gynecology, University of Chicago, Chicago, IL, USA
In preparation for PrEP delivery, many studies examined the expected barriers and facilitators, as well as PrEP awareness, among ciswomen in the USA, including specifically among Black ciswomen [4-16]. These studies revealed barriers that are now familiar: side effects, low HIV risk perception, costs, lack of awareness, low provider engagement, medical mistrust, stigma, fear of disclosure, and concerns about daily pill taking. Limited data on PrEP use show low rates of continuation or adherence among ciswomen [17-19], ranging from $37.5 \%$ to $41 \%$ retention at 6 months among predominantly Black ciswomen. However, few studies have examined the experiences of Black ciswomen actually using PrEP in real-world settings $[12,13,17]$. In this analysis, we look at both patient characteristics and in-depth interviews to understand and characterize the PrEP experience, particularly PrEP persistence, among Black ciswomen who have initiated PrEP.

\section{Methods}

The study was primarily conducted at Howard Brown Health, a large, urban federally qualified health center $(\mathrm{FQHC})$ in Chicago, IL, with a focus on sexual and gender minority 
health. Since 2016, the FQHC has recently expanded into primarily Black neighborhoods and has increased engagement with Black ciswomen. We used a mixed-methods approach, in which quantitative and qualitative work iteratively informed the research questions.

For the quantitative analysis, all self-identified Black ciswomen who had started PrEP from January 1, 2015 through February 1, 2019 were included; to be able to account for neighborhood characteristics, we excluded patients residing outside of Chicago. All data came from electronic health records (EHRs) and included 6 months of follow-up. Residential zip codes were linked to zip code level HIV prevalence data [20]; we also included neighborhood (South, West, or North), by zip code, which captures both neighborhood demographics and distance to clinics. Other EHR data included demographics, PrEP prescriptions, PrEP provider, HIV/STI tests, and the patient's reason for scheduling the visit. In response to information from the qualitative interviews, we also matched each patient's PrEP provider to human resources (HR) data on race and gender, and determined whether patients had been to Howard Brown Health prior to their first PrEP prescription.

Persistence was defined as having proportion of days covered $\geq 86 \%$ for each of the first 6 months of PrEP use, according to prescription data [21]; this translates into having at least six doses per week for the entire first 6 months of PrEP use. Logistic regressions were used to model PrEP persistence, first using each covariate independently and then in an adjusted model, using variables chosen a priori.

For the qualitative analysis, we included only active patients, from both Howard Brown Health and the University of Chicago's Infectious Disease Clinic and Sexual Wellness Clinic, and purposefully selected Black ciswomen who did and did not achieve PrEP persistence at 6 months to gather a range of experiences; patients are described in the text by their age, PrEP persistence at 6 months, and whether they were still using PrEP at the time of the interview. Sixty-one patients were included in the sampling frame. A total of 29 participants were successfully contacted to assess interest in participating in the qualitative interview. Of those who were successfully contacted, 16 agreed to participate and 8 were eligible, consented, and completed informant interviews; of note, the COVID-19 pandemic began in the middle of the study, which impacted recruitment and availability for interviews. A semistructured interview guide was developed and used to capture information on PrEP awareness in their community, perception of HIV risk, and experience starting and using PrEP. Interviews were conducted either in-person or via phone by trained research assistants; all interviews were recorded and then transcribed. Transcripts were uploaded into Dedoose, a cloud-based mixed-methods software, for analysis. Interviews were analyzed using a deductive thematic content analysis approach. A preliminary code book was created based on the interview guide and a transcript selected at random; all coders $(N=3)$ reviewed and revised the preliminary codes. Next, the codebook was applied by the primary coder to two transcripts, secondary coders coded a subset of excerpts selected at random and achieved reliability at $>0.80$. Most divergences occurred due to omission and upon review were quickly rectified to $100 \%$ agreement. Codes were then applied to all eight transcripts and were reviewed by all three coders for consensus of code application. Finally, themes were created based on clustering of code application.

This study was approved by the IRBs at the University of Chicago, Lurie Children's Hospital, and Howard Brown Health. All participants in the qualitative interviews gave informed verbal consent; consent was waived for the quantitative analysis. Quantitative analysis was conducted in SAS 9.4; qualitative analysis was conducted in Dedoose.

\section{Results}

Among 112 Black ciswomen who initiated PrEP during the study period, $73 \%$ were 35 years old or younger and 58\% identified as straight (Table 1). More than half used public insurance. At half of PrEP initiation visits, the visit reason was specifically PrEP or post-exposure prophylaxis (PEP) to PrEP; 28\% were for PEP/STI/HIV testing visits. Most participants were from the Southside of Chicago, with an average zip code-level HIV prevalence of $1.2 \%$.

Overall, total time on PrEP (including gaps) was 8.1 months on average and PrEP persistence at 6 months was $18 \%$ (Table 2). Persistence was highest among those age 26-35 years $(27 \%)$, with private insurance $(29 \%)$, from the Northside (35\%) or where HIV prevalence was $<1.0 \%$ (27\%). In the final adjusted model, neighborhood was significant, with the odds of persistence lower in West and Southside residents compared to Northside; visit reason was also significant, with PrEP visits significantly associated with higher odds of persistence compared to "other" visit reasons, although the CIs were wide. Year of PrEP initiation was also associated with persistence; each recent year had lower odds of persistence, although the trend may not be strictly linear. Age, orientation, and insurance were not associated with persistence.

\section{Introduction to PrEP}

Black ciswomen in this study learned about PrEP in a variety of ways, often recalling more than one "introduction" to PrEP. Some were motivated to learn about PrEP because a partner or relative had HIV.

Because of my-a sibling. He ended up being positive, my little brother. So, that's how I researched, because I 
Table 1 Characteristics of Black ciswomen at PrEP initiation

\begin{tabular}{|c|c|}
\hline & $\begin{array}{l}\text { Total } \\
\%(N)\end{array}$ \\
\hline$N$ & 112 \\
\hline \multicolumn{2}{|l|}{ Age } \\
\hline $18-25$ & $40.2(45)$ \\
\hline $26-35$ & $33.0(37)$ \\
\hline $36-45$ & $14.3(16)$ \\
\hline $46+$ & $12.5(14)$ \\
\hline \multicolumn{2}{|l|}{ Orientation } \\
\hline Straight & $58.0(65)$ \\
\hline Bisexual & $23.2(26)$ \\
\hline Lesbian/queer & $7.1(8)$ \\
\hline Other & $11.6(13)$ \\
\hline \multicolumn{2}{|l|}{ Insurance } \\
\hline Private & $18.8(21)$ \\
\hline Public & $61.6(69)$ \\
\hline Self-pay/uninsured & $19.6(22)$ \\
\hline \multicolumn{2}{|l|}{ Provider gender } \\
\hline Female & $59.8(67)$ \\
\hline Male & $25.0(23)$ \\
\hline Genderqueer & $13.0(12)$ \\
\hline \multicolumn{2}{|l|}{ Provider race } \\
\hline Black & $31.3(35)$ \\
\hline White & $57.1(64)$ \\
\hline Latinx & $6.3(7)$ \\
\hline Other & $5.4(6)$ \\
\hline Patient prior to PrEP initiation & $50.9(57)$ \\
\hline \multicolumn{2}{|l|}{ Chicago region (by zip code) } \\
\hline North & $23.2(26)$ \\
\hline West & $19.6(22)$ \\
\hline South & $57.1(64)$ \\
\hline Mean HIV prevalence (by zip code) & $1.2(0.6)$ \\
\hline \multicolumn{2}{|l|}{ Visit reason at PrEP initiation } \\
\hline $\mathrm{PrEP} / \mathrm{PEP}$ to PrEP & $50.9(57)$ \\
\hline $\mathrm{PEP} / \mathrm{STI} / \mathrm{HIV}$ & $27.7(31)$ \\
\hline Other & $21.4(24)$ \\
\hline \multicolumn{2}{|l|}{ Year of PrEP initiation } \\
\hline 2015 & $7.1(8)$ \\
\hline 2016 & $7.1(8)$ \\
\hline 2017 & $32.1(36)$ \\
\hline 2018 & $47.3(53)$ \\
\hline 2019 & $6.3(7)$ \\
\hline
\end{tabular}

got scared and I was, like-yeah, it has to be something out here. Then I saw a commercial on ... the web. I think Facebook. (34, persisted \& on PrEP)

Others learned about it through their work (usually in HIV) or from others who worked in HIV.
I started taking PrEP - a friend of mine-well, somebody that I know at Howard Brown, came to me and they told me about PrEP. They gave me information on it and I told them I wasn't sure. So, three weeks later I went back to the clinic and I made-I had an appointment, and I... talking to somebody and that's when I started PrEP. (40, persisted \& on PrEP)

Three ciswomen reported learning about PrEP from a provider and agreed to try it; one case was specifically related to her own STI test, one was related to a partner's HIV care, and one was part of a youth program at Howard Brown. This supports the finding in the quantitative analysis, where we found that $28 \%$ of initiation visits had PEP, STI, or HIV testing listed as the original visit reason.

I went to a doctor's appointment with my then boyfriend.... Actually he, you know, well, we wanted to see how to, you know, move about the relationship.... The provider-told us about it. (35, persisted \& on PrEP)

I heard about PrEP when I went to get a checkup... So, once I got to Howard Brown, Howard Brown educated me on what PrEP was and, you know, the exposure and everything to it. So, yeah, I opted right in at the moment I heard about it. (35, persisted \& no longer on PrEP)

Regardless of how they learned of PrEP, many ciswomen researched PrEP themselves and brought it up to their provider. This finding echoes the quantitative results, where we found that $51 \%$ of ciswomen initiating PrEP had PrEP listed as their visit reason.

So, then, I went on of course Google... I found out that there was the medication that was called PrEP, and there was like different brands, but Truvada was like the one that was like sticking out at that time. So then, I researched physicians who I felt comfortable going to and like saying, 'Hey, I want to get on this medication because my partner is positive, and I wanna make sure that I remain negative.' So, researched doctors... and he was like, 'You know what? No problem,' so he just explained to me what some of the options were... so I chose to start with PrEP.... I had plenty of questions. So, definitely my biggest questions-because I like to research items, I wanted to know what were the side effects of PrEP? I wanted to know how long should a person take PrEP? How long did it take for it to be active in your system after you started taking it, like how long should I wait before [we] were intimate? Let's see; I also wanted to know what were any side effects or any precautionary measures I should take if we wanted to start having kids, like you know, what should I do? So, there were plenty of questions that I had when I went in. (39, persisted \& no longer on PrEP) 
Table 2 PrEP persistence at first 6 months

\begin{tabular}{|c|c|c|c|}
\hline & $\%$ Persistent $(N)$ & $\begin{array}{l}\text { OR }(95 \% \mathrm{CI}) \\
p \text { value }\end{array}$ & $\begin{array}{l}\mathrm{aOR}(95 \% \mathrm{CI}) \\
p \text { value }\end{array}$ \\
\hline Age & & $p=0.26$ & $p=0.07$ \\
\hline $18-25$ & $13.3(6)$ & $0.56(0.12,2.63)$ & $0.20(0.02,1.86)$ \\
\hline $26-35$ & $27.0(10)$ & $1.36(0.31,5.90)$ & $1.08(0.15,7.68)$ \\
\hline $36-45$ & $6.3(1)$ & $0.24(0.02,2.68)$ & $0.09(0.006,1.54)$ \\
\hline $46+$ & $21.4(3)$ & ref & ref \\
\hline Orientation & & $p=0.86$ & $p=0.69$ \\
\hline Straight & $16.9(11)$ & ref & ref \\
\hline Bisexual & $23.1(6)$ & $1.47(0.48,4.51)$ & $2.31(0.51,10.5)$ \\
\hline Lesbian/queer & $12.5(1)$ & $0.70(0.08,6.29)$ & $1.85(0.15,23.6)$ \\
\hline Other & $15.4(2)$ & $0.89(0.17,4.60)$ & $0.77(0.09,6.45)$ \\
\hline Insurance & & $p=0.34$ & $p=0.89$ \\
\hline Private & $28.6(6)$ & ref & ref \\
\hline Public & $14.5(10)$ & $0.42(0.13,1.35)$ & $0.87(0.19,4.04)$ \\
\hline Self-pay/uninsured & $18.2(4)$ & $0.56(0.13,2.34)$ & $1.27(0.21,7.65)$ \\
\hline Provider gender & & $p=0.40$ & \\
\hline Female & $14.9(10)$ & ref & \\
\hline Male & $25.8(8)$ & $1.98(0.70,5.66)$ & \\
\hline Genderqueer & $14.3(2)$ & $0.95(0.18,4.90)$ & \\
\hline Provider race & & $p=0.62$ & \\
\hline Black & $14.3(5)$ & ref & \\
\hline White & $17.2(11)$ & $1.25(0.40,3.93)$ & \\
\hline Latinx & $28.6(2)$ & $2.40(0.36,15.9)$ & \\
\hline Other & $33.3(2)$ & $3.0(0.43,21)$ & \\
\hline Prior patient & & $p=0.16$ & \\
\hline New patient & $22.8(13)$ & $2.03(0.74,5.54)$ & \\
\hline Region (by zip code) & & $p=0.04$ & $p=0.02$ \\
\hline North & $34.6(9)$ & ref & ref \\
\hline West & $13.6(3)$ & $0.30(0.07,1.29)$ & $0.12(0.02,0.82)$ \\
\hline South & $12.5(8)$ & $0.27(0.09,0.81)$ & $0.17(0.04,0.71)$ \\
\hline HIV prevalence & & $p=0.11$ & \\
\hline$<1.0$ & $27.3(12)$ & ref & \\
\hline$<2.0$ & $13.5(7)$ & $0.42(0.15,1.17)$ & \\
\hline$\geq 2.0$ & $6.3(1)$ & $0.18(0.02,1.50)$ & \\
\hline Chief complaint & & $p=0.17$ & $p=0.02$ \\
\hline PrEP/PEP to PrEP & $24.6(14)$ & $2.28(0.59,8.81)$ & $8.34(1.27,54.9)$ \\
\hline $\mathrm{PEP} / \mathrm{STI} / \mathrm{HIV}$ & $9.7(3)$ & $0.75(0.14,4.10)$ & $1.32(0.14,12.1)$ \\
\hline Other & $12.5(3)$ & ref & ref \\
\hline First PrEP year & & $0.50(0.31,0.81), p=0.004$ & $0.34(0.17,0.68) p=0.002$ \\
\hline 2015 & $62.5(5)$ & & \\
\hline 2016 & $0(0)$ & & \\
\hline 2017 & $29.4(27)$ & & \\
\hline 2018 & $51.1(47)$ & & \\
\hline
\end{tabular}

Unfortunately, such efforts were not always successful (although this participant did eventually initiate PrEP at a different clinic).

I'm-well, my doctor at the time-physician at the time, I was like I'm going to start dating and I-I think PrEP is an option for me. And they were like no, PrEP is not an option for you because you're not considered high risk. (25, did not persist)

\section{Provider and Clinic Interactions}

Most ciswomen did not have providers of the same race and/ or gender. While some suggested race and gender concordance would improve trust with their provider, most said it was not a barrier and that their providers found other ways to develop trust. This was reflected in the quantitative analysis, where neither provider race nor gender were associated with persistence (Table 2).

So, he was not the same ethnicity as me, and I was-and I'm African American, I was looking for a doctor who was African American. But for me, he made me feel so comfortable when I came in; it wasn't judgmental; he even invited me to-ask me to invite my husband to come in so that he could ask questions, as well. So, I think that that kinda broke down that uneasiness, and it wasn't challenging for me. But I think that if that would not have happened initially, I probably would have 
either looked for another doctor who was of the same nationality or probably had a more understanding for people of color. (39, persisted \& no longer on PrEP)

However, one ciswoman felt her race led to a provider to treat her differently.

I'm thinking, 'Well, probably because I'm black, a black woman, he probably thought I was a prostitute because I had a STD and I was coming to the emergency room.' But that wasn't unusual to me, for a person to think. You know, and then they took me to a private area and stuff like that. (49, did not persist)

This participant further described the lack of rapport with her provider.

You know, because I didn't really have no sexual partner. It was something that I did with the ex, and that was that. And I explained that to [the doctor]; I did explain that to him... but I didn't understand why he was giving it to me... I didn't ask for it.... That's why he gave me [PrEP]; he didn't believe. (49, did not persist)

Ciswomen also discussed the other types of support they got through the clinic (see the section on costs below). One ciswoman in particular mentioned the support she and her husband received as a serodiscordant couple.

One of the things that I really loved when I started was that myself and my husband had a social worker.... You know, so she would, you know, call and check up even we didn't have those appointments and even, you know, doctors, they're busy.... But I think it makes a big difference when somebody's just checking in on you. (35, persisted \& on PrEP)

One ciswoman reported needing help remembering refills and appreciating the flexibility of the clinic in accommodating her and describes the ways in which barriers to access are lowered:

You know, like whereas Howard Brown, I could literally call and even if I have an appointment coming up or I need an appointment, they're like, 'Hey, I'll put this one refill through, but you have to come in, get your blood work.' Even during the pandemic they're like, 'All right, we're closed, but,' you know, 'Hey, we're closed this week, but I'm putting your prescription through. Go pick it up.' (35, persisted \& on PrEP)

Throughout the interviews, ciswomen commented on the similarities between PrEP and birth control - and some felt it should be approached in a similar way by clinicians:
I think that when it comes to those questionnaires and it says how many sexual partners have you had... I think there needs to be more of a conversation like if you're having sex and you don't know maybe what the other partner is doing - or you may know but just another way of protecting yourself, we have this medication that's for you. And then, explain what it's-what it's for. I think it should be-I think it should be brought up like any other medicine. Even I think it should be-like I don't use birth control. It should be brought up like birth control.... And if you offer birth-doctors offer birth control all of the time. (25, did not persist)

\section{Costs of PrEP}

Payment and insurance, including job changes, were inconveniences for some, but never a reason for stopping; while women with private insurance were more likely to be persistent, this was not significant in the adjusted models. Most ciswomen felt they were supported by the clinic and pharmacy to get affordable medication.

It was a gap only because my insurance wouldn't pay for it.... But the social worker here helped me get a prescription, helped me get a discount card-Because at first, I was going to have to pay a lot of money out of pocket - and I wouldn't be able to do that. (34, persisted \& on PrEP)

You wait for your insurance to kick in. As soon as it kicked in, you know, they're like, 'Hey, we don't have a appointment for two, three weeks.' And I literally had to call and have the nurse like have the doctor call me, and I literally like almost had to beg. Like I understand, you know, you need to see me first, but, you know, Ineed this medication [laughs]. (35, persisted \& on PrEP, in regard to changing jobs)

\section{Motivations for Using PrEP}

Ciswomen articulated a variety of reasons for what motivated their PrEP use, both as explanations to themselves and to others. One ciswoman, explaining how she would disclose to a partner, focused on her own health and well-being.

'But I wanna be here for you and for us, for me. And I wanna be the best means of - the best version of me, and that's why I chose to take this,' so I think it needs to come from that standpoint. (39, persisted \& no longer on PrEP) 
Many ciswomen related their PrEP use to trust with their partner.

But even if -I feel like and maybe I'm wrong for this but Ifeel like even if I'm having sex with one partner-and if I don't know what my partner is doing then, why can't I take the medicine? (25, did not persist)

Related to trust, ciswomen expressed that PrEP made them feel safe, one participant explaining that this alone should be enough to motivate adherence.

The fact that, the fact that you feel safe when you take the pill should be enough. I'm just being honest. (35, persisted \& not on PrEP)

Finally, one ciswoman explained how sexual risk can be hard to predict and can decrease motivation to stay on PrEP:

I think when you're not active it kinda makes it hard because you probably think like, 'Okay, I'm not doing anything-_' -I don't need to take it.' But the reality is, life happens and you don't know, you might feel one way one day and the next day you might see somebody, 'Oh, I know that person,' and fling happens, whatever. (34, persisted \& on PrEP)

\section{Stopping PrEP}

Five ciswomen had stopped taking PrEP, some after years on PrEP. Most decisions to stop were multifactorial, often a combination of changes in relationships, side effects, and pregnancy concerns. For instance, one ciswoman (with a partner living with controlled HIV) made the decision to stop based on side effects and concerns about PrEP use during pregnancy:

I think the biggest thing - well, the biggest deciding factor for me was we were trying to start a family, and no one really had any research on how it affected someone who was pregnant. So, I think that was the biggest determining factor of why I stopped. (39, persisted \& no longer on PrEP)

Another ciswoman was also concerned about side effects and pregnancy; however, conversations with her partner led to a monogamous relationship where she felt PrEP was no longer needed. Other ciswomen reported relationships becoming exclusive as reasons to stop PrEP as well.

And by me being in my 30s and trying to conceive, I didn't know the side effects when it came to, um, trying to have a baby with taking PrEP will... So, if I'm trying to build a family and I'm taking PrEP, I don't know, you know, the outcome. There's not a lot of information out there as far as having a baby. (35, persisted \& no longer on PrEP)

In combination with severe side effects that she felt unprepared for, one ciswoman reported that not knowing others on PrEP led to her decision to stop.

But when I did take the PrEP, okay, I took it-yeah, I took it maybe three times, for three days in a row. And by the third day, I got so sick I knew exactly what it was because it was the only thing that - that I was using in my body that was-that was foreign.... And that kinda scared me too because it was something that nobody that I knew personally or unpersonally, because I asked about it. And I know gay people that was not taking it, so it kinda concerns - that kinda concerns me too. $(49$, did not persist)

No ciswomen reported daily adherence as a reason to stop PrEP, although one woman stated a preference for a weekly or monthly product, underscoring the importance of options in HIV prevention strategies. In general, women did not report adherence as a problem, often referring to their experience taking birth control pills.

So, it was kinda like my college days when I was taking birth control pills, and I was like, 'Hey,' and I popped at night before I went to bed, and that's how I remember, it was part of my nighttime routine: before you go bed, it was next to my bed, take it, and that's it. So, it wasn't hard at all. (39, persisted \& not on PrEP)

\section{Community Perspectives on PrEP}

Consistently, the interviewees thought other ciswomen in their community were at high risk for HIV but uneducated about PrEP. Some ciswomen mentioned PrEP awareness through commercials, which could be in a positive light.

I mean, TV, social media, I've seen it, you know, I've seen quite a few, even celebrities, you know, come out about it a couple of years ago. There was like a big PrEP movement, well, what I thought was a big PrEP movement. I wanna say like two years ago or something like that where I was seeing it a lot, you know, a whole lot. And I was like really happy. (35, persisted \& on PrEP)

However, some commercials were related to malpractice lawsuits and may have led to negative views toward PrEP. 
The ad that I seen on TV-I can tell you about the first one that I seen. It was advertisement special PrEP and they were talking about how it's to prevent HIV and if you have, like, any health problems, like, diabetes, then they were saying, like there's risk factors if you have health problems. At then the second commercial I've see about PrEP was they were talking about where people who took PrEP have liver failure. (40, persisted \& on PrEP)

Most ciswomen felt that advertising was focused on other demographics and not on ciswomen. Again, the importance of safe conception came up as a suggestion for commercials.

Even in the commercials, you see trans, you see, you know, you see gay men. I don't think that women-I-I don't know how to explain it. Like I don't think that they realize that it's not just a - especially in the black community, like HIV is such a gay thing. Like me and my husband literally like shut down in the middle of conversations because people like, 'No, it's a men, gay,' you know. It's-it's literally is like if a man or woman got it, you know, one of them is gay. Like it's such a-it's such a stigma, whereas I feel like if there was like, you know, a-and I mean, it's hard to explain it in a commercial. But it's like, 'Oh, we had a healthy,' you hear 'em saying, 'a marriage and a baby,' like even a flash of like them on a date, them getting married, them having a baby, and then it's like thanks to PrEP. You know, or something like that, I know that sounds kinda silly, but I don't think people look at it that way. (35, persisted \& on PrEP)

As the quote above also describes, there was also stigma around HIV and PrEP. Another ciswoman described confusion from others about PrEP meaning that she had HIV.

So, I don't think it's the fear of PrEP, it's just a fear of those-you know, 'Why you on it? Are you sure don't have it,' (34, persisted \& on PrEP)

Importantly, almost none of the ciswomen reported knowing other ciswomen on PrEP. Ciswomen saw a need not only for PrEP education but also for engagement with each other:

I think that if we had someplace where we had cisgender or women-heterosexual women that's not positive-that can come to ask these questions and feel comfortable with asking these questions then, that would help close some of these gaps. Right now, all of these locations are so far-or it's such stigmas around these clinics - that people don't want to go. We're trying to break those barriers. But if I had a place I can go to, walk in, people know that this is not a place for HIV.
This is a place I'm going to ask questions about STIs or just, you know, PrEP-around PrEP. (25, did not persist)

One ciswoman clearly laid out the barriers, both individual and systemic, to PrEP use for ciswomen in her community and highlighted the ways she was able to overcome them, recognizing that this may not be possible for everyone:

... I'm like, 'There were no commercials when I was researching five years ago,' no one really knew about this, it was like a hush-hush. So, I think for women, it needs to be: No. 1, they need to know about, and know that it's out there, and know why you use it. It's not just a magic pill that you take that gives you free rein, you still gotta protect yourself. So, definitely, them having the knowledge and the options, and then too having access to healthcare. I'm very fortunate that I was able to have access to healthcare, even when I wasn't working during an expanse at that time, I was able to go and-I knew how to go and try to find healthcare for myself so that I could continue with the PrEP. So, it's like you know having that access to healthcare. And then, having people who are compassionate and not judgmental, because for whatever reason, doctors need to know, nurses need to know that women need to protect themselves, period. It doesn't matter what their lifestyle is or what they're doing; we just want them to be well and want them to be safe. But I think that message needs to get out there without it being judgmental.... So, for me, it was just being understanding that I wanna protect myself, I wanna protect my kids and my family, you know, the future of my family, and I'm just thankful that I had options and means, and I just wish that all women had that, as well. (39, persisted \& not on PrEP)

\section{Discussion}

In the present study, we found that Black ciswomen's experience using PrEP echoed the initial PrEP literature in many ways, including low awareness of PrEP, the importance of providers in PrEP decision-making, and barriers like HIV/ PrEP stigma and side effects. However, there were several unique findings, especially concerns around safety during pregnancy, the active role ciswomen took in protecting themselves, and the lack of peer support. In addition, we did not find that potential barriers, like cost or daily regimens, were concerns among those who started PrEP. Finally, while PrEP persistence was low in our study population, the qualitative interviews suggest that ciswomen were often making PrEP decisions based on their HIV risk perception. 
Most studies report that fewer than $40 \%$ of Black ciswomen are aware of PrEP [10-14]; diffusion of knowledge has been slow. Most participants interviewed in our study had learned about PrEP outside of the clinic, although some did have providers initially bring it up. Most of this knowledge was positive, but some lawsuit-related commercials may have led to negative perceptions $[22,23]$. We also saw in the quantitative results that having PrEP as the primary visit reason was associated with increased persistence; one interpretation is that ciswomen who have learned about PrEP and are internally motivated are more likely to stick with PrEP. Finally, we found that Black ciswomen were very engaged in the PrEP decision-making process. Together this suggests that increasing community awareness of PrEP among Black ciswomen, as well as non-judgmental PrEP education in the clinic, could improve uptake and persistence $[13,14,24]$.

Our work also highlighted the role of providers in PrEP initiation and persistence [13]. Even without racial or gender congruency, ciswomen described how providers were able to develop rapport with them, which seemed to support their PrEP practice; this is an important skill given historical traumas and current medical mistrust among many minority groups [16]. However, one participant had a counter experience, feeling judged and unheard by her provider and quickly stopping PrEP. This also highlights the tension between developing internal versus external motivation to use PrEP and allowing ciswomen time and agency to ask questions about PrEP. However, as awareness of PrEP was low, ciswomen suggested that providers discuss PrEP more often, especially during other conversations around sex and contraception, a strategy that could improve access $[9,25,26]$.

Two other important areas for providers to consider are side effects and pregnancy. Almost all the participants described experiencing side effects; preparing ciswomen with anticipatory counseling around side effects and how to deal with side effects may improve persistence. Pregnancy also came up as a concern among Black ciswomen and sometimes as a reason for stopping PrEP. Pregnancy is a time of increased risk of HIV acquisition [27]. The effects of tenofovir-based oral PrEP, as well as among women living with HIV, on pregnancy and offspring have been studied [28-31]. The CDC guidelines find no evidence of increased risk and the WHO states "Based on the available safety data, WHO considers that PrEP should not be discontinued during pregnancy and breastfeeding for women who continue to be at substantial risk of HIV infection. PrEP can also be considered as an additional prevention choice for HIV-negative pregnant women who are at substantial risk of HIV infection, as part of a comprehensive PMTCT package" $[32,33]$. Providers can help ciswomen make informed decisions around their fertility plans and HIV risks by providing evidence-based information about the safety and benefits of PrEP during conception, pregnancy, and post partum.
While some ciswomen had become advocates within their social circles, many had not disclosed their PrEP use and few knew of other ciswomen on PrEP, similar to other work [12]; the participants also saw other ciswomen in their community as at risk for HIV but generally unaware of PrEP. This finding echoes the need for increased PrEP awareness - especially, as the participants pointed out, featuring and using messages relating to Black ciswomen. Participants frequently reported that PrEP was seen as something only for MSM or transgender individuals. Themes of trust, safety, and family frequently came up regarding PrEP and should be further explored to develop culturally appropriate and inclusive messages [6, 34]. In addition, one participant clearly outlined the need to provide support groups for ciswomen to discuss their experience, preferably outside of an HIV clinic, also reflected in the literature [24]. As peers have often been used in HIV treatment, this may be an effective strategy for HIV prevention as well $[24,35,36]$.

We did not find that costs associated with PrEP were a barrier to persistence, in either the qualitative or quantitative results, contrary to some previous studies $[9,26]$. However, this may be related to the PrEP navigation team and pharmacy partners, who are well-versed in PrEP discount and coverage programs. We did find that ciswomen on the Northside of Chicago, a somewhat higher income and racially mixed area, had higher persistence, compared to those from the Southside (a lower income and predominantly Black area). This may suggest that distance to clinics and/or socioeconomic factors are structural barriers to PrEP access [13].

Contrary to concerns in the previous literature, most ciswomen in the qualitative analysis did not report concerns about adherence; one study found similar expectations around pill taking [8]. Many of the ciswomen had experience with oral birth control pills and saw PrEP as a similar product that they already knew how to use. However, some ciswomen did express an interest in other regimens; as injectable and vaginal ring PrEP may be available soon, there is a need to prepare community and providers in order to improve PrEP uptake and awareness of these new methods.

Finally, we saw evidence of prevention-effective adherence among the ciswomen interviewed [37]. Some ciswomen started PrEP explicitly due to a partner living with HIV, dating frequently, or being in a non-monogamous relationship. Some participants also stopped when relationships became monogamous or a partner was virally suppressed (usually along with other concerns). And ciswomen recognized the difficulty of assessing their risk, as not all sex is planned in advance. Providers can empower ciswomen to make choices and reduce HIV acquisition risk, even though they may not meet strict PrEP criteria [38].

The strengths of this study include the recruitment of PrEPexperienced ciswomen in real-world clinical settings and the integration of qualitative and quantitative results. However, 
study results need to be interpreted considering some limitations. The study recruited from a large urban jurisdiction, primarily from a sexual-health focused clinic system with extensive PrEP navigation and support services; results may not be generalizable to other settings, such as rural locales or clinics with less PrEP support services. Only $48 \%$ of our sampling frame was contacted and $50 \%$ of those enrolled, due in part to the COVID-19 pandemic; it is unknown how the patients who did not participate differ from those who did. The study was conducted to ensure rigor and reproducibility by recording data objectively through audio and professional transcription, and using a documented coding scheme in data analysis and interpretation [39].

\section{Conclusions}

While only $18 \%$ of Black ciswomen persisted on PrEP at protective levels for 6 months, qualitative results suggest women were often making decisions based on their changing HIV risk perception. Actual experience with PrEP among our participants overlaps in some ways with the expected facilitators and barriers but there were important differencesespecially concerns around PrEP use and pregnancy. At the community level, developing culturally appropriate PrEP messages to increase awareness and finding ways for ciswomen to connect with peers could lead to improved PrEP uptake and persistence. Within clinics, PrEP navigators can play an important role in supporting both patients and providers in PrEP delivery. Finally, there are important ways in which providers can better deliver PrEP to ciswomen in high prevalence areas, including developing rapport, discussing side effects and pregnancy, and integrating PrEP discussions into standard sexual/reproductive health practices.

Acknowledgments We recognize all the patients and staff at Howard Brown Health and University of Chicago Medicine for their time and participation in this work.

Authors' Contributions J.P.R., L.R.H., S.H., C.B., M.G., A.K.J., and M.P. developed the research questions and acquired funding. S.D., A.Z.U., S.I., and E.S. collected data; A.J.K. oversaw the qualitative analysis and M.P. conducted the quantitative analysis. MP drafted the manuscript; all authors reviewed and contributed to the manuscript.

Funding This work was supported by an administrative supplement to the Third Coast Center for AIDS Research (CFAR), an NIH-funded program (P30 AI117943).

\section{Declarations}

Ethics Approval This study was approved by the IRBs at the University of Chicago, Lurie Children's Hospital, and Howard Brown Health. All participants in the qualitative interviews gave informed verbal consent; consent was waived for the quantitative analysis.

\section{References}

1. CDC. HIV and Women. Centers for Disease Control and Prevention. 2020 [cited 2020 Sep 22]. Available from: https:// www.cdc.gov/hiv/group/gender/women/index.html.

2. Tools \& Resources. AIDSVu. [cited 2020 Sep 22]. Available from: http://aidsvu.org/resources/.

3. Siegler AJ, Mehta CC, Mouhanna F, Giler RM, Castel A, Pembleton E, et al. Policy- and county-level associations with HIV pre-exposure prophylaxis use, the United States, 2018. Ann Epidemiol. 2020;45:24-31.e3.

4. Auerbach JD, Kinsky S, Brown G, Charles V. Knowledge, attitudes, and likelihood of pre-exposure prophylaxis (PrEP) use among US women at risk of acquiring HIV. AIDS Patient Care STDs. 2014;29:102-10.

5. Bond KT, Gunn AJ. Perceived advantages and disadvantages of using pre-exposure prophylaxis (PrEP) among sexually active black women. J Black Sex Relatsh. 2016;3:1-24.

6. Calabrese SK, Dovidio JF, Tekeste M, Taggart T, Galvao RW, Safon CB, et al. HIV pre-exposure prophylaxis stigma as a multidimensional barrier to uptake among women who attend planned parenthood. JAIDS J Acquir Immune Defic Syndr. 2018;1.

7. Carley T, Siewert E, Naresh A. Interest in pre-exposure prophylaxis (PrEP) for HIV is limited among women in a general obstetrics \& gynecology setting. AIDS Behav. 2019;23:2741-8.

8. Flash CA, Stone VE, Mitty JA, Mimiaga MJ, Hall KT, Krakower D, et al. Perspectives on HIV prevention among urban black women: a potential role for HIV pre-exposure prophylaxis. AIDS Patient Care STDs. 2014;28:635-42.

9. Goparaju L, Praschan NC, Warren-Jeanpiere L, Experton LS, Young MA, Kassaye S. Stigma, partners, providers and costs: potential barriers to PrEP uptake among US women. J AIDS Clin Res. 2017 [cited 2018 Jul 18];8. Available from: https://www.ncbi.nlm. nih.gov/pmc/articles/PMC5708581/.

10. Hill LM, Lightfoot AF, Riggins L, Golin CE. Awareness of and attitudes toward pre-exposure prophylaxis among African American women living in low-income neighborhoods in a Southeastern city. AIDS Care. 2020;1-5.

11. Johnson AK, Fletcher FE, Ott E, Wishart M, Friedman EE, Terlikowski J, et al. Awareness and intent to use pre-exposure prophylaxis (PrEP) among African American women in a family planning clinic. J Racial Ethn Health Disparities. 2020;7:550-4.

12. Hirschhorn LR, Brown RN, Friedman EE, Greene GJ, Bender A, Christeller C, et al. Black cisgender women's PrEP knowledge, Attitudes, preferences, and experience in Chicago. J Acquir Immune Defic Syndr. 2020;84:497-507.

13. Nydegger LA, Dickson-Gomez J, Ko Ko T. A longitudinal, qualitative exploration of perceived HIV risk, healthcare experiences, and social support as facilitators and barriers to PrEP adoption among black women. AIDS Behav. 2020 [cited 2020 Sep 16]; Available from: https://doi.org/10.1007/s10461-020-03015-9.

14. Raifman JR, Schwartz SR, Sosnowy CD, Montgomery MC, Almonte A, Bazzi AR, et al. Brief Report: Pre-exposure prophylaxis awareness and use among cisgender women at a sexually transmitted disease clinic. J Acquir Immune Defic Syndr. 2019;80:36-9.

15. Sales JM, Steiner RJ, Brown JL, Swartzendruber A, Patel AS, Sheth AN. PrEP eligibility and interest among clinic- and community-recruited young black women in Atlanta, Georgia, USA. Curr HIV Res. 2018;16:250-5. 
16. Tekeste M, Hull S, Dovidio JF, Safon CB, Blackstock O, Taggart T, Kershaw TS, Kaplan C, Caldwell A, Lane SB, Calabrese SK Differences in medical mistrust between black and white women: implications for patient-provider communication about PrEP. AIDS Behav. 2018 [cited 2019 Feb 19]; Available from: https:// doi.org/10.1007/s10461-018-2283-2.

17. Blackstock OJ, Patel VV, Felsen U, Park C, Jain S. Pre-exposure prophylaxis prescribing and retention in care among heterosexual women at a community-based comprehensive sexual health clinic. AIDS Care. 2017:1-4.

18. Marcus JL, Hurley LB, Hare CB, Nguyen DP, Phengrasamy T, Silverberg MJ, et al. Preexposure prophylaxis for HIV prevention in a large integrated health care system: adherence, renal safety, and discontinuation. J Acquir Immune Defic Syndr. 2016;73:540-6.

19. Rolle C-P, Onwubiko U, Jo J, Sheth AN, Kelley CF, Holland DP. PrEP implementation and persistence in a county health department setting in Atlanta, GA. AIDS Behav. 2019;23:296-303.

20. Data Methods - ZIP Code, Community area/ward, census tract. AIDSVu. [cited $2019 \mathrm{Feb} 11]$. Available from: https://aidsvu.org/ data-methods/data-methods-zip-code-census-tract/.

21. Pyra M, Rusie L, Castro M, Keglovitz Baker K, McNulty M, Bohm $\mathrm{N}$, et al. A taxonomy of pragmatic measures of HIV preexposure prophylaxis use. AIDS. 2020;34:1951-7.

22. What's Behind the Recent Media Ads Looking for PLWH and People Taking PrEP with Side Effects From Truvada?. POZ. 2019 [cited 2020 Sep 30]. Available from: https://www.poz.com/ article/behind-recent-media-ads-looking-plwh-people-taking-prepside-effects-truvada.

23. Serrano PA, Daubert E, Munoz A, Hosek SG, French AL. Effect of Truvada lawsuit advertising on PrEP attitudes and decisions among sexual and gender minority youth and young adults at risk for HIV. AIDS. 2020 [cited 2020 Oct 8];Publish Ahead of Print. Available from: https://journals.lww.com/aidsonline/Abstract/9000/Effect_ of_Truvada_lawsuit_advertising_on_PrEP.96592.aspx.

24. Nydegger LA, Dickson-Gomez J, Ko TK. Structural and syndemic barriers to PrEP adoption among Black women at high risk for HIV: a qualitative exploration. Cult Health Sex. 2020;0:1-15.

25. Calabrese SK, Krakower DS, Mayer KH. Integrating HIV preexposure prophylaxis (PrEP) into routine preventive health care to avoid exacerbating disparities. Am J Public Health. 2017;107: 1883-9.

26. Ojikutu BO, Mayer KH. Hidden in plain sight: identifying women living in the United States who could benefit from HIV preexposure prophylaxis. J Infect Dis. [cited 2019 Oct 7]; Available from: http:// academic.oup.com/jid/advance-article/doi/10.1093/infdis/jiz416/ 5573044.

27. Thomson KA, Hughes J, Baeten JM, John-Stewart G, Celum C, Cohen CR, et al. Increased risk of female HIV-1 acquisition throughout pregnancy and postpartum: a prospective per-coital act analysis among women with HIV-1 Infected Partners. J Infect Dis. 2018;218:16-25.
28. Mugo NR, Hong T, Celum C, Donnell D, Bukusi EA, John-Stewart $\mathrm{G}$, et al. Pregnancy incidence and outcomes among women receiving preexposure prophylaxis for HIV prevention: a randomized clinical trial. JAMA. 2014;312:362-71.

29. Joseph Davey DL, Pintye J, Baeten JM, Aldrovandi G, Baggaley R, Bekker L-G, et al. Emerging evidence from a systematic review of safety of pre-exposure prophylaxis for pregnant and postpartum women: where are we now and where are we heading? J Int AIDS Soc. 2020;23:e25426.

30. Nachega JB, Uthman OA, Mofenson LM, Anderson JR, Kanters S, Renaud F, et al. Safety of tenofovir disoproxil fumarate-based antiretroviral therapy regimens in pregnancy for HIV-infected women and their infants: a systematic review and meta-analysis. J Acquir Immune Defic Syndr. 2017;76:1-12.

31. Mofenson LM, Baggaley RC, Mameletzis I. Tenofovir disoproxil fumarate safety for women and their infants during pregnancy and breastfeeding. AIDS. 2017;31:213-32.

32. Preexposure prophylaxis for the prevention of HIV infection in the United States - 2017 Update: a clinical practice guideline. Centers for Disease Control and Prevention, US Public Health Service; 2017. Available from: https://www.cdc.gov/hiv/pdf/risk/prep/cdchiv-prep-guidelines-2017.pdf.

33. WHO Technical Brief: Preventing HIV during pregnancy and breastfeeding in the context of PrEP. Geneva, Switzerland: WHO; 2017. Available from: http://www.who.int/hiv/pub/toolkits/preppreventing-hiv-during-pregnancy/en/.

34. Park C, Taylor T, Rios N, Khedimi R, Weiss C, Dolce E, et al Perspectives of women prescribed HIV pre-exposure prophylaxis (PrEP). Open Forum Infect Dis. 2017;4:S440.

35. Simoni JM, Nelson KM, Franks JC, Yard SS, Lehavot K. Are peer interventions for HIV efficacious? A systematic review. AIDS Behav. 2011;15:1589-95.

36. Genberg BL, Shangani S, Sabatino K, Rachlis B, Wachira J, Braitstein $\mathrm{P}$, et al. Improving engagement in the HIV care cascade: a systematic review of interventions involving people living with HIV/AIDS as peers. AIDS Behav. 2016;20:2452-63.

37. Haberer JE, Bangsberg DR, Baeten JM, Curran K, Koechlin F, Amico KR, et al. Defining success with HIV pre-exposure prophylaxis: a prevention-effective adherence paradigm. AIDS. 2015;29: 1277-85.

38. Calabrese SK, Willie TC, Galvao RW, Tekeste M, Dovidio JF, Safon CB, et al. Current US guidelines for prescribing HIV preexposure prophylaxis (PrEP) disqualify many women who are at risk and motivated to use PrEP. J Acquir Immune Defic Syndr. 2019;81:395-405.

39. Seale C, Silverman D. Ensuring rigour in qualitative research. Eur J Pub Health. 1997;7:379-84.

Publisher's Note Springer Nature remains neutral with regard to jurisdictional claims in published maps and institutional affiliations. 